\title{
The association between the regular use of risk-based term IOL and improved birth outcomes in an Italian hospital: A retrospective cohort study
}

\author{
G. Del Boca ${ }^{1}$, A. Biffi ${ }^{1}$, R. Zagni ${ }^{1}$, A. Montanari ${ }^{2}$ and J.M. Nicholson ${ }^{3 *}$ \\ ${ }^{1}$ Department of Obstetrics and Gynecology, Mandic Hospital, Italy \\ ${ }^{2}$ Department of Anesthesia, Papa Giovanni XXIII, Italy \\ ${ }^{3}$ Department of Family and Community Medicine, Milton S. Hershey Medical Center of Pennsylvania State University, USA
}

\begin{abstract}
Objective: Associations have been recently reported between the regular use of risk-based term labor induction and improvements in birth outcomes. We wanted to study the use of this approach in an Italian hospital.

Design: Retrospective Cohort Study

Setting: The Mandic Hospital, in Merate, Italy, from March 2009 through July 2010.

Population: All pregnant women delivering at term who met study inclusion and exclusion criteria.

Methods: The "exposed" group was comprised of women cared for and delivered by providers who regularly offered risk-based term labor induction. The "nonexposed" group was comprised of women cared for and delivered by providers who followed the "expectant management" approach to risk. Prenatal, intrapartum and outcome data for the two cohorts were collected and compared.
\end{abstract}

Main outcome measures: Cesarean delivery rate and weighted Adverse Outcome Index (AOI) Score.

Results: The exposed group ( $\mathrm{n}=120)$, as compared to the non-exposed group ( $\mathrm{n}=159)$, had a higher induction rate, a lower cesarean rate (1.7\% vs. $43.4 \%$, aOR 0.04, CI [0.01-0.22]), and a numerically lower weighted Adverse Outcome Index Score (0.4 vs. 6.1, p=0.61). Two cases of term stillbirth occurred in the non-exposed group. No adverse birth outcome occurred with greater frequency in the exposed group.

Conclusion: In this Italian hospital, and consistent with previous studies, exposure to the regular use of risk-based term labor induction was associated with a more favorable set of birth outcomes. Randomised clinical trials are needed to further explore this alternative approach.

\section{Introduction}

Rates of cesarean delivery (CD) have increased dramatically in the USA [1], in Italy [2], and throughout the world [3]. Possible reasons include the modern option of patient-choice $\mathrm{CD}$, medicallegal pressures to deliver "un-injured" babies, and an increasing number of medical indications for $\mathrm{CD}$ [4-6]. As compared to 30 years ago, pregnant women in developed countries now tend to be older, heavier, and more likely to have medical conditions linked to CD [7-9]. However, despite calls from various sectors to reverse rising CD rates $[10,11]$, there has been little success in developing methods of care that safely reduce $\mathrm{CD}$ utilization $[12,13]$.

The safe reduction of $\mathrm{CD}$ rates is desirable because $\mathrm{CD}$, as compared to vaginal delivery, is linked to higher rates of post-partum infection [14,15], excessive blood loss [16], and neonatal intensive care unit (NICU) admission [17]. In addition, CD is associated with longer hospital stays for both mother and baby $[18,19]$, increased frequency of serious complications during future pregnancies [18], and higher costs [20]. Despite suggestions that elective CD might improve maternal perineal health $[21,22]$, its long-term benefits are unproven $[16,23]$, and its long-term risks have probably been minimized [24,25].
Consequently, the identification of a method of care that could safely reduce $\mathrm{CD}$ remains an important goal [26].

Several published retrospective cohort studies described associations between exposure to an alternative method of care called the Active Management of Risk in Pregnancy at Term (AMOR-IPAT) and unusually low group CD rates $(0.8 \%-11 \%)$ [24,27-30]. AMOR-IPAT begins with the assessment of each pregnancy's pattern of common prenatal risk factors. This assessment is then used to estimate, for each pregnancy, an upper limit of the optimal time of delivery (UL-OTD)

Correspondence to: James M. Nicholson, MD, MSCE, Department of Family and Community Medicine, Milton S. Hershey Medical Center of Pennsylvania State University, 500 University Drive, Hershey, PA 17033, USA, Tel: 484-802 7782/ 717-531-8182, Fax: 717-531-5024,E-mail: jnicholson@hmc.psu.edu, jnicholson@hmc.psu.edu

Key words: induction of labour, risk-based labor induction, cesarean delivery, weighted Adverse Outcome Index Score, birth outcomes

Received: February 06, 2017; Accepted: February 26, 2017; Published: February 28,2017 
[24,28-31]. The greater a pregnancy's composite risk of CD for either cephalo-pelvic disproportion (CPD) or utero-placental insufficiency (UPI), the earlier the pregnancy's estimated UL-OTD [31]. Pregnant women at term who do not develop spontaneous labour as they near their UL-OTD are offered induction of labour (IOL). In contrast to an indicated IOL (i_IOL), where there is the identification of a specific high-risk state that justifies the IOL, a risk-based IOL (rb_IOL) is based on modeling of multiple intermediate-risk states. If the offer of a rb_IOL is accepted by a pregnant woman, then the IOL is scheduled so that the woman delivers on or just before her UL-OTD [32]. If a pregnant woman who is scheduled for a rb-IOL has an unfavorable uterine cervix (Bishop's score $<6$ ), then pre-induction cervical ripening is recommended [32-34]. The purpose of this investigation was to see if the previously reported associations between AMOR-IPAT exposure and the safe reduction of $\mathrm{CD}$ rate could be replicated with the use of AMOR-IPAT in an Italian hospital.

\section{Methods}

We employed a retrospective cohort study design to compare the outcomes of women exposed to the AMOR-IPAT method of care (hereinafter "the exposed group") to the outcomes of women who received usual obstetric care (hereinafter "the unexposed group"). All deliveries for this study occurred between March 2009 and July 2010 at Mandic Hospital in Merate, Italy. AMOR-IPAT exposure involved first the estimation of the UL-OTD for each exposed woman. A scoring sheet for UL-OTD estimation is included as Appendix A. To minimise the risk of iatrogenic neonatal pulmonary problems related to an incorrectly dated early-term risk-based IOL, ultrasound determination of pregnancy dating was obtained on all pateints in either the first trimester or the early second trimester. In this study, a gestational age of $37 \mathrm{w} 3 \mathrm{~d}$ days was used as the lower limit of the optimal time of delivery (LL-OTD) for all exposed gravidas. If a woman exposed to AMOR-IPAT developed spontaneous labour before her UL-OTD, then her labour and delivery was managed in the usual manner. However, if spontaneous labour did not develop by 3-4 days prior to her UL-OTD, then she was offered rb_IOL so that she could deliver 1-3 days before her UL-OTD. In addition, if a woman was scheduled for a rb_IOL but her cervix was not favorable (i.e., modified cervical Bishop's score < $\left.6^{21}\right)$, then cervical ripening was promoted using Prostaglandin E2 pledget (Cervidil) and/or PGE2 gel (Propess). The protocol for cervical ripening and IOL used at Mandic Hospital is included as Appendix B. All women receiving $\mathrm{rb}_{-}$IOL were counseled with regards to the potential increased risk of cesarean delivery following IOL, and women offered rb_IOL prior to 39 weeks 0 days gestation were counseled with regards to the potential increased risk of both fetal lung immaturity and NICU admission in the early-term period of pregnancy. Permission to perform this retrospective study was obtained from the Mandic Hospital and from the institutional review board of the University of Pennsylvania (Protocol \#811046, approved 1/27/2011).

In this study, women in the exposed group received all of their pregnancy care (prenatal care and delivery care) from a group of three providers who routinely used the Del Boca AMOR-IPAT protocol (Appendix B). Women in the non-exposed group received all of their pregnancy care from a group of four obstetric physicians and/or eight midwives. Women who received no prenatal care, or whose care was provided by members of both groups, were excluded from the study. Inclusion criteria included singleton pregnancy, regular prenatal care with providers with clinical privileges at the study institution, and delivery on or after $37 \mathrm{w}$ 0d gestation. Exclusion criteria included prior cesarean delivery, any other previous transmural uterine surgery, HIV infection, major fetal anomaly, history of major pelvic injury, or any factor precluding a trial of labour.

Data concerning prenatal variables, intrapartum events, and clinical outcomes were abstracted from the charts of each identified mother-baby pair. The resulting data were then entered into an Excel database. Missing values were obtained by rechecking hospital records, or by contacting a woman's primary maternity care provider. Data were then transferred into the STATA Statistical Program (version 9, College Station, TX) for data analysis.

The Student's T test and the Wilcoxon rank-sum test were used to compare distributions of continuous demographic variables, past medical/surgical historical details, obstetric risk factors and outcomes present in the two study groups. Univariate chi-square tests were used to compare rates of various dichotomous prenatal risk factors, intrapartum variables, and birth outcomes in the two study groups. Statistical significance was determined by a p-value $\leq 0.05$ for the primary outcome (cesarean delivery rate), and a $p$-value of $\leq 0.01$ for all other comparisons and outcomes. Initially, analyses were performed comparing the two main study groups. In addition, some analyses were performed for each of two specific parity groups: nulliparous and multiparous. Data relating to the timing of delivery, mode of labour onset, and method of delivery were collated according to gestational age, collapsed into half-week sub-strata and encoded to enable graphic representation.

The strength of association between cesarean delivery and a variety of co-variates, including AMOR-IPAT exposure, were further assessed using multiple logistic regression. Clinical factors related to the use of AMOR-IPAT (e.g., birth weight, gestational age at delivery, indication for induction) were excluded from the final model due to concerns that they might lie in the causal chain between the lack of delivery before the UL-OTD and cesarean delivery.

To evaluate the possibility that exposure to AMOR-IPAT could have been associated with increased rates of various adverse outcomes, rates of multiple adverse birth outcomes for each group were determined and compared using both chi-square analysis and logistic regression. Rates of salient birth outcomes were also determined as a function of each of the two parity sub-groups. In addition, a summary outcome measurement called the weighted Adverse Outcome Index score (wAOI score) [35] was used to estimate the overall impact of AMOR-IPAT exposure on birth outcomes in the two study groups. Variables involved with the wAOI score are listed in Table 5 [35]. Finally, a "number needed to treat" (NNT) analysis was performed to estimate the number of women who would need to be exposed to the AMOR-IPAT method of care to prevent one cesarean delivery.

\section{Results}

During the study period, 1080 deliveries occurred at the study hospital and the overall hospital cesarean delivery rate was $34.6 \%$. 180 women delivered without having local prenatal care, 350 women had a uterine scar precluding a trial of labour, 70 women had some other problem precluding a trial of labour (breech presentation, fetal anomaly, placenta previa, herpes infection), 80 women delivered at or before 37 weeks 3 days of gestation, 100 women received obstetric care from both groups of providers, and 21 women had incomplete data. Of the remaining women, 120 were treated by providers who utilised AMORIPAT (the exposed group) and 159 were treated by providers who used the standard approach to prenatal risk (the non-exposed group). 
Table 1 presents levels of prenatal risk factors present in the two study groups. The exposed group was more likely to be multiparous $(51.7 \%$ vs. $23.9 \%, \mathrm{p}<0.001)$, was younger (median age 23 years vs. 25.9 years, $\mathrm{p}<0.001)$, and had a lower preconception body mass index (BMI) (median BMI at conception 22.0 vs. $24.3 \mathrm{~kg} / \mathrm{m}^{2}$ ). Distributions of race and nationality were also statistically significantly different. Maternal height and gestational weight gain were similar in the two study groups. Table 2 presents levels of intrapartum factors in the two study groups. Women in the exposed group delivered earlier in the term period $(38.4$ weeks vs. 40.4 weeks, $\mathrm{p}<0.001)$ and had a higher overall IOL rate $(70.8 \%$ v. $33.3 \%, \mathrm{p}<0.001)$. The two groups had similar cervical Bishop's scores on admission (3.6 vs. 3.4, $\mathrm{p}=0.56$ ).

Table 3 presents information concerning birth outcomes based on initial univariate analysis. The exposed group had a significantly lower cesarean delivery rate ( $1.7 \%$ vs. $43.4 \%)$, and significantly lower rates of cesarean delivery rates were associated with AMOR-IPAT exposure in both nulliparous and multiparous sub-groups. There were no NICU admissions in either group, but two cases of term stillbirth occurred in the nonexposed group ( $0 \%$ vs. $1.3 \%, \mathrm{p}=0.22$ ). Low APGAR scores at one and five minutes were rare and occurred at similar rates in the two groups.

Figure 1A shows the distribution of deliveries by week of gestational age in the two study groups. The exposed group delivered earlier in the term period. Figure 1B shows the frequencies of the types of labour onset as a function of gestational age in the two study groups. The exposed group experienced a more frequent overall use of IOL in general, and more frequent IOL in the $38^{\text {th }}$ and $39^{\text {th }}$ week. Figure $1 \mathrm{C}$ shows the incidence of vaginal delivery and $\mathrm{CD}$ as a function of gestational age in the two study groups. The exposed group experienced more frequent vaginal delivery.

Table 4 presents information from the final logistic regression modeling of the association between AMOR-IPAT exposure and CD. The final model included six factors: AMOR-IPAT exposure status (exposed vs. nonexposed), parity group (nulliparous or multiparous), high starting weight $(\geq 80 \mathrm{~kg})$, short stature $(\leq 157 \mathrm{~cm})$, excessive gestational weight gain ( $\geq 13 \mathrm{~kg}$ ), and geographical origin. Adjustment for these important covariates did not alter the magnitude of association

Table 1. Prenatal Variables by Study Group.

\begin{tabular}{|c|c|c|c|c|c|}
\hline Variable name & $\begin{array}{c}\text { Exposed } \\
(n=120)\end{array}$ & $\begin{array}{c}\text { Non-Exposed } \\
(n=159)\end{array}$ & Risk Ratio & $95 \% \mathrm{CI}$ & $\begin{array}{c}\mathbf{p} \\
\text { value }\end{array}$ \\
\hline \multicolumn{6}{|l|}{ Demographics } \\
\hline Age, mean & 31.6 yrs. & 30.2 yrs. & & & $<0.02$ \\
\hline Advanced Age ( $\geq 35$ years at delivery) & $27.5 \%$ & $22.6 \%$ & 1.21 & $0.81-1.83$ & 0.35 \\
\hline \multicolumn{6}{|l|}{ Geographical Designation: } \\
\hline Arabian & $8.3 \%$ & $13.8 \%$ & 0.60 & $0.30-1.22$ & 0.15 \\
\hline African & $5.8 \%$ & $11.3 \%$ & 0.52 & $0.22-1.19$ & 0.11 \\
\hline Italian & $77.5 \%$ & $56.6 \%$ & 1.37 & $1.16-1.62$ & $<0.001$ \\
\hline European, other & $5.0 \%$ & $13.2 \%$ & 0.38 & $0.16-0.91$ & 0.02 \\
\hline Asia (southern) & $3.3 \%$ & $3.8 \%$ & 0.88 & $0.25-3.06$ & 0.84 \\
\hline South American & $0 \%$ & $1.3 \%$ & - & - & 0.22 \\
\hline \multicolumn{6}{|l|}{ Maternal Habitus } \\
\hline Preconception weight, mean & $61.3 \mathrm{~kg}$ & $66.9 \mathrm{~kg}$ & & & $<0.001 * *$ \\
\hline High Preconception weight $\geq 80 \mathrm{~kg}$ & $7.1 \%$ & $17.8 \%$ & 0.40 & $0.19-0.84$ & 0.01 \\
\hline Height, mean & $1.65 \mathrm{~m}$ & $1.64 \mathrm{~m}$. & & & $0.49^{*}$ \\
\hline Short stature $(\leq 158 \mathrm{~cm})$ & $5 \%$ & $10.7 \%$ & 0.47 & $0.19-1.15$ & 0.09 \\
\hline Preconception BMI, mean $\left(\mathrm{kg} /\left[\mathrm{m}^{2}\right]\right)$ & 22.0 & 24.3 & & & $<0.001^{*}$ \\
\hline High BMI $\left(\geq 30 \mathrm{~kg} /\left[\mathrm{m}^{2}\right]\right)$ & $2.4 \%$ & $11.5 \%$ & 0.21 & $0.05-0.93$ & 0.02 \\
\hline \multicolumn{6}{|l|}{ Index Pregnancy } \\
\hline Nulliparous Status & $48.3 \%$ & $76.1 \%$ & 0.64 & $0.52-0.78$ & $<0.001^{*}$ \\
\hline Weight Gain during pregnancy, mean & $12.9 \mathrm{~kg}$ & $14.3 \mathrm{~kg}$ & --- & --- & 0.02 \\
\hline Excess weight gain $(\geq 13 \mathrm{~kg})$ & $43.4 \%$ & $51.7 \%$ & 0.84 & $0.64-1.1$ & 0.18 \\
\hline
\end{tabular}

*Calculated with the Mann Whitney rank-sum test

Table 2. Admission and Intrapartum Variables by Study Group.

\begin{tabular}{|c|c|c|c|c|c|}
\hline Variable name & & $\begin{array}{c}\text { Non-Exposed } \\
(\mathbf{n}=\mathbf{3 0 0})\end{array}$ & Risk Ratio & $95 \% \mathrm{CI}$ & $\begin{array}{c}p \\
\text { value }\end{array}$ \\
\hline \multicolumn{6}{|l|}{ Woman Status on Admission } \\
\hline Gestational age at delivery, all (median) & $38.4 \mathrm{wks}$ & 40.4 wks & - & - & $<0.0001^{*}$ \\
\hline Gest age on admission, nullip (median) & $38.4 \mathrm{wks}$ & 40.4 wks & - & - & $<0.0001$ \\
\hline Gest age on admission, multip (median) & 38.4 wks & 40.69 wks & - & - & $<0.0001$ \\
\hline Post Dates Delivery (> 41 weeks) & $0 \%$ & $23.9 \%$ & - & - & $<0.0001$ \\
\hline Initial Bishop's Score (mean) & 3.6 & 3.4 & - & - & $0.56^{*}$ \\
\hline Initial Bishop's Score (very low, i.e., $\leq 1$ ) & $5.0 \%$ & $6.9 \%$ & 0.72 & $0.28-1.90$ & $0.51^{*}$ \\
\hline Vertex Presentation & $100 \%$ & $100 \%$ & - & - & 1.00 \\
\hline \multicolumn{6}{|l|}{ Intra-Partum Interventions } \\
\hline Induction of labour, all & $70.8 \%$ & $33.3 \%$ & 2.12 & $1.66-2.72$ & $<0.0001$ \\
\hline Induction of labour, nulliparous & $69.0 \%$ & $35.5 \%$ & 1.94 & $1.44-2.61$ & $<0.0001$ \\
\hline Induction of labour, multiparous & $72.6 \%$ & $26.3 \%$ & 2.76 & $1.59-4.80$ & $<0.0001$ \\
\hline
\end{tabular}

$26.3 \%$

2.76

$1.59-4.80$

$<0.0001$ 
Table 3. Cesarean Delivery, Neonatal and AOI Score Information by Study Group.

\begin{tabular}{|c|c|c|c|c|c|}
\hline & Exposed & Non-Exposed & Relative Risk & 95\% CI & p value \\
\hline \multicolumn{6}{|l|}{ Overall Cesarean Delivery Rate } \\
\hline All Study Subjects & $\begin{array}{c}1.7 \% \\
(2 / 120)\end{array}$ & $\begin{array}{c}43.4 \% \\
(69 / 159)\end{array}$ & 0.04 & $0.01-0.15$ & $<0.0001$ \\
\hline \multicolumn{6}{|l|}{ CESAREAN DELIVERY RATE PARITY GROUP } \\
\hline Nulliparous only ** & $\begin{array}{l}1.7 \% \\
(1 / 58)\end{array}$ & $\begin{array}{c}52.1 \% \\
(63 / 121)\end{array}$ & 0.03 & $0.01-0.23$ & $<0.0001$ \\
\hline Multiparous only $* *$ & $\begin{array}{l}1.7 \% \\
(1 / 62)\end{array}$ & $\begin{array}{l}15.8 \% \\
(6 / 38)\end{array}$ & 0.10 & $0.01-0.82$ & 0.007 \\
\hline \multicolumn{6}{|l|}{ Cesarean Delivery Rate By Mode Of Onset } \\
\hline Spontaneous labour ** & $\begin{array}{l}2.9 \% \\
(1 / 35)\end{array}$ & $\begin{array}{c}39.6 \% \\
(42 / 106)\end{array}$ & 0.7 & $0.01-0.50$ & $<0.0001$ \\
\hline Induction of labour ** & $\begin{array}{c}1.2 \% \\
(1 / 84)\end{array}$ & $\begin{array}{c}50.9 \% \\
(27 / 53)\end{array}$ & 0.02 & $0.01-0.64$ & $<0.0001$ \\
\hline \multicolumn{6}{|l|}{ Cesarean Delivery Rate By Both Parity Group And Mode Of Onset } \\
\hline Nulliparous and Spontaneous Labour ** & $\begin{array}{l}5.6 \% \\
(1 / 17)\end{array}$ & $\begin{array}{l}47.4 \% \\
(37 / 78)\end{array}$ & 0.06 & $0.02-0.80$ & 0.001 \\
\hline Nulliparous and IOL $* *$ & $\begin{array}{c}0 \% \\
(0 / 26)\end{array}$ & $\begin{array}{l}60.5 \% \\
(26 / 43)\end{array}$ & - & - & $<0.0001$ \\
\hline Multiparous and Spontaneous Labour ** & $\begin{array}{c}0 \% \\
(0 / 17)\end{array}$ & $\begin{array}{l}17.9 \% \\
(5 / 28)\end{array}$ & - & - & 0.06 \\
\hline Multiparous and $\mathrm{IOL}^{* *}$ & $\begin{array}{l}2.2 \% \\
(1 / 45)\end{array}$ & $\begin{array}{c}10.0 \% \\
(1 / 9)\end{array}$ & 0.22 & $0.02-3.26$ & 0.23 \\
\hline \multicolumn{6}{|l|}{ Neonatal Intensive Care Unit Admission Rate } \\
\hline Overall NICU Admission Rate & $0 \%$ & $0 \%$ & - & - & - \\
\hline \multicolumn{6}{|l|}{ Term Fetal Mortality Rate } \\
\hline Overall Term Fetal Mortality & $\begin{array}{r}0 \% \\
(0 / 120)\end{array}$ & $\begin{array}{c}1.3 \% \\
(2 / 159)\end{array}$ & - & - & 0.22 \\
\hline \multicolumn{6}{|l|}{ Apgar Scoring } \\
\hline 1-Minute APGAR, mean & 9.1 & 8.4 & - & - & $<0.001 * * *$ \\
\hline APGAR@1 minute $\leq 4$ & $\begin{array}{r}1.7 \% \\
(2 / 120)\end{array}$ & $\begin{array}{c}1.9 \% \\
(3 / 159)\end{array}$ & 0.88 & $0.15-0.89$ & 0.89 \\
\hline 5-Minute APGAR, mean & 9.7 & 9.3 & - & - & $<0.001 * * *$ \\
\hline APGAR@ 5 minutes $\leq 7$ & $\begin{array}{c}1.7 \% \\
(2 / 120)\end{array}$ & $\begin{array}{c}2.5 \% \\
(4 / 159)\end{array}$ & 0.66 & $0.12-3.56$ & 0.63 \\
\hline \multicolumn{6}{|l|}{ Cord Blood Gas Information } \\
\hline Cord $\mathrm{pH}$, mean & 7.28 & 7.27 & - & - & $0.81 * * *$ \\
\hline Cord $\mathrm{pH}<7.2$ & $\begin{array}{c}10.8 \% \\
(13 / 120)\end{array}$ & $\begin{array}{c}16.1 \% \\
(25 / 155)\end{array}$ & 0.67 & $0.36-0.26$ & 0.21 \\
\hline Cord $\mathrm{pH}<7.1$ & $\begin{array}{r}2.5 \% \\
(3 / 120)\end{array}$ & $\begin{array}{l}3.9 \% \\
(6 / 155)\end{array}$ & 0.65 & $0.16-2.53$ & 0.53 \\
\hline \multicolumn{6}{|c|}{ WEIGHTED ADVERSE OUTCOME INDEX (“wAOI”) SCORE (See Table 5) } \\
\hline WEIGHTED ADVERSE OUTCOME INDEX (“wAOI”) SCORE & 0.4 & 6.1 & _ & - & $0.61 * * *$ \\
\hline
\end{tabular}

*when not specified, rates are based on entire study group

** rates calculated based on sub-strata

***by Wilcoxon rank-sum analysis

between AMOR-IPAT exposure and lower CD rate.

Table 5 shows that the wAOI score was lower in the exposed group ( 0.4 vs. $6.1, \mathrm{p}=0.61$ ), but this finding was heavily influenced by the occurrence of two term stillbirths in the non-exposed group (one at 40w $1 \mathrm{~d}$ and one at 41w 4d). Both stillbirths delivered well after their pregnancy's estimated UL-OTD and were therefore theoretically preventable. The NNTs for exposure to AMOR-IPAT to prevent one $\mathrm{CD}$ were 2.4 for the entire group, 2.0 for nulliparous women and 7.1 for multiparous women.

\section{Discussion}

\section{Main findings}

Exposure of pregnant women at term to the regular use of risk-based IOL (AMOR-IPAT) was associated with a significantly lower CD rate (1.7\%) as compared to women receiving usual care (43.4\%). Exposure
Table 4. Logistic Regression Modeling of AMOR-IPAT exposure on cesarean delivery.

\begin{tabular}{|l|l|l|l|}
\hline Variables* & Unadjusted RR & Adjusted OR's & $\begin{array}{l}\text { Adjusted 95\% } \\
\text { Confidence Intervals }\end{array}$ \\
\hline AMOR-IPAT exposure & 0.04 & 0.04 & $(0.01-0.16)$ \\
\hline Nulliparity & 5.11 & 6.04 & $(2.11-17.30)$ \\
\hline $\begin{array}{l}\text { High Starting Weight } \\
(\geq 80 \mathrm{~kg})\end{array}$ & 1.56 & 1.61 & $(0.62-4.19)$ \\
\hline Short Stature ( $\leq 62 ”)$ & 1.62 & 1.64 & $(0.51-5.29)$ \\
\hline $\begin{array}{l}\text { Excess Weight Gain } \\
(\leq 13 \mathrm{~kg})\end{array}$ & 1.40 & 1.32 & $(0.64-2.70)$ \\
\hline Arabian & 1.00 & 1.00 & $(1.17-3.04)$ \\
\hline African & 2.89 & 1.17 & $(1.17-3.04)$ \\
\hline Italian & 1.33 & 0.60 & $(0.60-7.89)$ \\
\hline European & 1.82 & 0.50 & $(0.40-10.50)$ \\
\hline Asia (southern) & 1.85 & 0.33 & $(0.33-35.84)$ \\
\hline South America & 4.33 & 0.08 & $(0.08-39.18)$ \\
\hline
\end{tabular}

*Listed according to decreasing significance within the final logistic model $* *$ Statistically significant $(\mathrm{p}<0.05)$ 
1. AMOR-IPAT Exposed

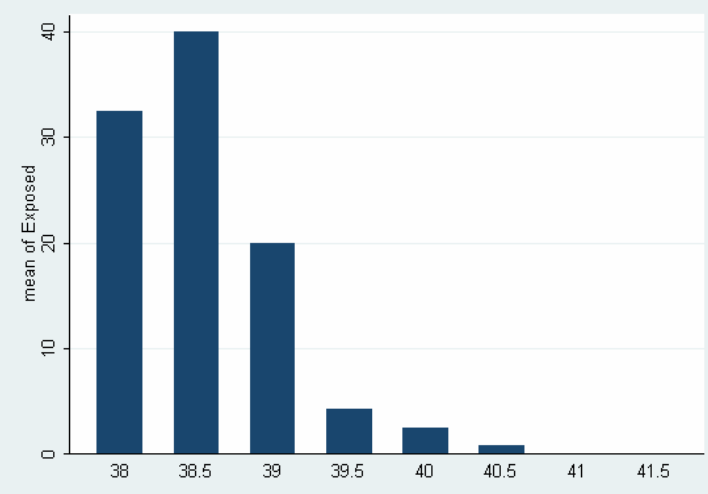

2. Non-Exposed

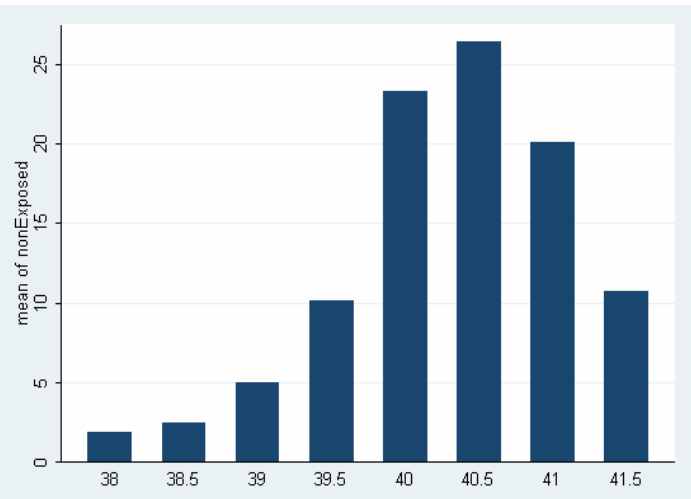

Figure 1A. Distribution of timing of delivery, as a function of gestational age, by study group.

1. AMOR-IPAT Exposed

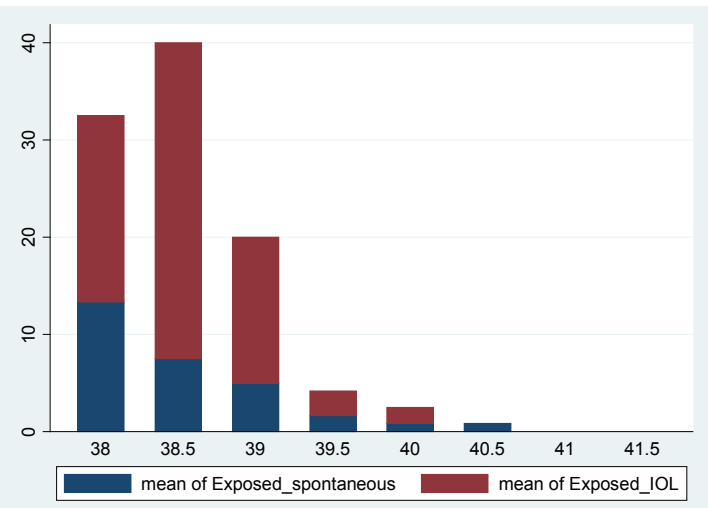

Figure 1B. Spontaneous vs. induced labour, as a function of gestation age, by study group.

\section{Non-Exposed}

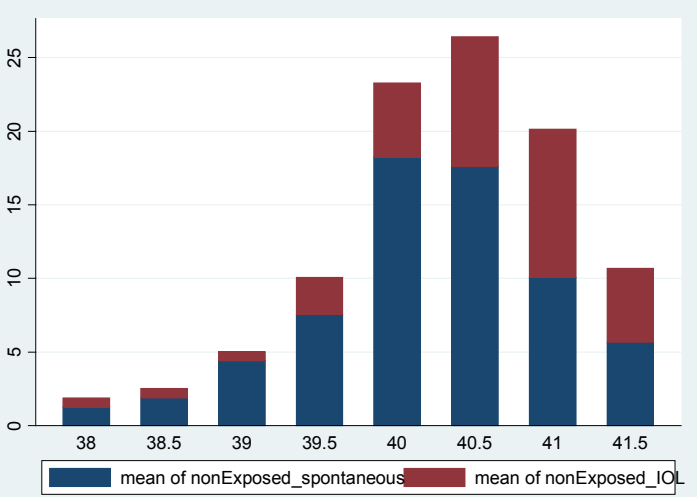

\section{AMOR-IPAT Exposed}

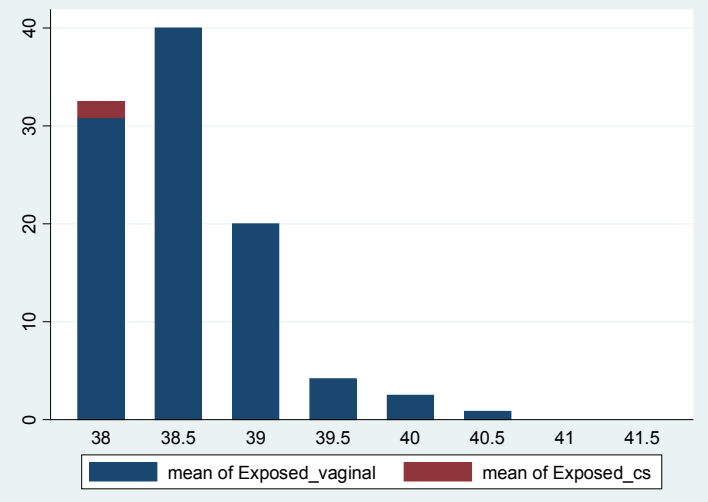

2. Non-Exposed

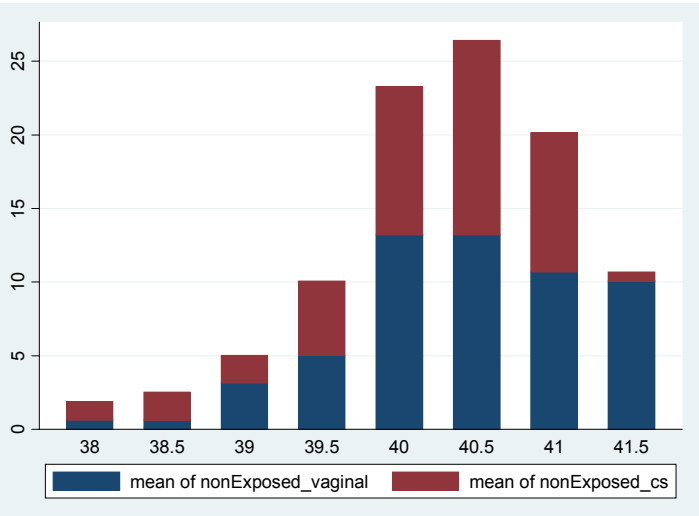

Figure 1C. Vaginal vs. cesarean delivery, as a function of gestational age, by study group.

was also associated with either significantly lower, or unchanged, rates of other adverse birth outcomes. The occurrence of two cases of stillbirth in the non-exposed group (one full-term term and one lateterm) highlights an area where the use of AMOR-IPAT might provide an extremely important benefit [36,37]. Recent evidence suggests that the recent adoption of a policy to delay all "non-indicated" deliveries until at least 39 weeks has been associated with a significant increase in the rate of term stillbirth in the USA [38].

\section{Strengths and limitations}

The strength of this study, and its importance, rests in both the history of its own development and in the general concept of translation of new ideas into clinical use. The providers caring for the women in the exposed group read published papers describing AMOR-IPAT, and applied this method of care to their own patient population. Whereas the original papers describing risk-based term IOL involved women 
Table 5. Adverse Outcome Index Information.

\begin{tabular}{|c|c|c|c|c|c|}
\hline Variable name & $\begin{array}{c}\text { Exposed } \\
(n=120)\end{array}$ & $\begin{array}{c}\text { Non-Exposed } \\
(\mathbf{n}=159)\end{array}$ & $\begin{array}{c}\text { AOI } \\
\text { Points }\end{array}$ & $\begin{array}{l}\text { Exposed } \\
\text { Points }\end{array}$ & $\begin{array}{c}\text { Non-Exposed } \\
\text { Points }\end{array}$ \\
\hline Maternal Death & 0 & 0 & 750 & 0 & 0 \\
\hline Term Stillbirth/Intrapartum/Perinatal Death & 0 & 2 & 400 & 0 & 800 \\
\hline Uterine Rupture & 0 & 0 & 100 & 0 & 0 \\
\hline Maternal Intensive Care Unit Admission & 0 & 0 & 65 & 0 & 0 \\
\hline Infant Birth Trauma & 0 & 2 & 60 & 0 & 120 \\
\hline Return to Operating Room & 0 & 0 & 40 & 0 & 0 \\
\hline Neonatal Intensive Care Unit Admission & 0 & 0 & 35 & 0 & 0 \\
\hline APGAR Score@5 min $<7$ & 2 & 2 & 25 & 50 & 50 \\
\hline Maternal Blood Transfusion & 0 & 0 & 20 & 0 & 0 \\
\hline Third or Fourth Degree Perineal Injury & 0 & 0 & 5 & 0 & 0 \\
\hline Total points & - & - & - & 50 & 970 \\
\hline Mean AOI Score & - & - & - & 0.4 & 6.1 \\
\hline
\end{tabular}

*Calculated with the Mann Whitney rank-sum test

from the Northeastern region of the USA, this paper describes the application of AMOR-IPAT to patients in Italy. As such, the apparent benefit found in this study provides evidence that the use of risk-based term IOL may be beneficial in multiple populations. Furthermore, the unusually low adjusted Odds Ratio (aOR) found for the association between "exposure" and CD rate (0.04) indicates the strong possibility of an underlying causal relationship [39]. Such a possibility is also suggested by the unusually strong aORs noted in previous AMORIPAT observational studies [24,27-30].

Three other recent studies highlight the concept that risk-based non-indicated IOL might be beneficial. First, a recent meta-analysis of all RCTs involving non-indicated IOL found that non-indicated IOL, as compared to expectant management, led to a lower cesarean delivery rate [40]. Second, a recent large retrospective study of Scottish women evaluated birth outcomes in women following non-indicated IOL at various weeks in the term period compared to expectant management and delivery later [41]. Non-indicated term IOL was associated with clinically meaningful and statistically significant decreased odds of term perinatal mortality at all weeks of gestation prior to the estimated date of confinement (EDC, or due date). Finally, a recent large retrospective study of Californian women, using the same approach as the Scottish study, found clinically meaningful and statistically significant decreased odds of CD with non-indicated IOL at every week of the term period, including the early term weeks [42]. Hence, the findings of this Italian study are consistent with a growing body of evidence suggesting that non-indicated IOL might be more beneficial than harmful. This study focuses on risk-based IOL, which, while currently considered a "nonndicated" type of IOL, might be now viewed as an acceptable "modeled indication" for early-term labor induction.

In contrast to our findings, many previous observational studies reported associations between delivery following IOL, as compared to delivery following spontaneous labour, and higher rates of various adverse birth outcomes [43-49]. However, studies comparing the outcomes of "indicated" IOL to the outcomes of spontaneous labour provide little useful information because, in the presence of an accepted indication, there is generally no choice but to initiate IOL $[49,50]$. Furthermore, even for women having a "non-indicated" IOL, there usually exist one or more risk factors that underlie the recommendation, or the request, for the IOL [51]. If women delivering after the spontaneous onset of labour are less likely to have risk factors than women having a "non-indicated" IOL, then the observational studies comparing the outcomes following IOL to the outcomes following spontaneous labour probably contain significant "confounding by indication" [52,53]. Finally, most of the observational studies that compared "non-indicated" IOL to spontaneous labour failed to correctly model the actual impact of ni_IOL on the flow of term pregnancy. Specifically, in deciding to perform a ni_ IOL, the actual choice is between delivery now (by "non-indicated" IOL) and delivery later (by either spontaneous labour, some type of IOL at a later date or pre-labour CS) $[41,42,54]$. Several recent cohort studies that used the correct modeling found that "non-indicated" IOL, as compared with expectant management to a later gestational age, was associated with lower rates of adverse birth outcomes including CD and term stillbirth [40-42,55].

We acknowledge that this study contains a number of limitations. First, it was retrospective and therefore potentially influenced by unknown confounders. Although logistic regression demonstrated that adjustment for known confounding variables did not alter the strength of study associations, it is possible that hidden confounders might have caused alterations in those associations. Second, this study occurred at a single Italian hospital and it is unclear whether our results are generalizable to other types of institutions, patient populations or geographic areas. However, the study population was of mixed ethnic and racial types, and its results are similar to other recently published studies of AMOR-IPAT that involved women of mixed ethnic and racial types. Third, the difference in the types of providers in the exposed group (obstetricians) and non-exposed group (obstetricians and midwives) raises the possibility of selection bias, information bias, and differences in practice style including threshold for CD. This type of bias, if present, could not be eliminated through the use of logistic regression. However, the presence of midwife providers in the nonexposed group would be expected to lower, not raise, the CD rate of that group [56]. Fourth, the study was not powered to evaluate the association between AMOR-IPAT exposure and infrequent adverse outcomes such as neonatal hyaline membrane disease, meconium aspiration syndrome, or neonatal mortality. However, there were no worrisome trends or "near misses" in the outcome data suggesting that maternal or neonatal outcomes would have been less favorable in the exposed group if the study had been larger. In fact, the opposite trends were present. Finally, the providers of AMOR-IPAT did not routinely perform amniocentesis prior to risk-based IOL in the earlyterm period of pregnancy [57]. However, a similar use of AMOR-IPAT in the setting of an RCT reported that AMOR-IPAT exposure led to a significantly lower NICU admission rate as compared to usual care. ${ }^{30}$ In addition, all observational studies of AMOR-IPAT have included risk-based IOL in the early-term period (i.e., the $37^{\text {th }}$ and $38^{\text {th }}$ weeks 
of gestation) and all have reported either lower or unchanged rates of NICU admission following AMOR-IPAT exposure $[18,20]$.

\section{Interpretation}

The estimation of individual UL-OTD and the regular use of risk-based IOL may enable women to avoid cesarean delivery in two ways: 1) the fetus may be slightly smaller and therefore better able to fit through the maternal pelvis, and 2) the placenta may be healthier and therefore better able to support the fetus during labor. The issue of a low pre-induction cervical Bishop's score may be addressed with the regular use of prostaglandin medication (PGE1 or PGE2) and/or Foley balloon catheters. By the $38^{\text {th }}$ week of gestation the human fetus may be ready for extra-uterine life if delivery is preceded by labor (i.e. following labour induction). Transition to extrauterine life in the $38^{\text {th }}$ week may be more difficult if delivery occurs via pre-labour cesarean section. .

\section{Conclusion}

This study found that the regular use of AMOR-IPAT, with its high rates of cervical ripening and risk-based IOL, as compared to usual care that involves expectant management until 41-42 weeks of gestation, was associated with a significantly lower group CD rate. Rates of other major adverse birth outcomes were not increased following exposure to AMOR-IPAT. In this study, the rate of perinatal mortality and the pattern of AOI scores trended higher in the usual care group, but did not reach statistical significance. AMOR-IPAT may represent a strategy able to provide for the safe reduction of group $\mathrm{CD}$ rates through the use of risk-based IOL. If there is serious interest in reducing high global rates of term cesarean delivery, then adequately powered, multi-site, prospective randomised clinical trials are needed that compare the outcomes following the regular use of risk-based "non-indicated" IOL to the outcomes of the expectant management of risk.

Disclosure of interests - Dr. Nicholson has provided grand rounds presentation on the topic of AMOR-IPAT at several academic institution, and was provided standard compensation for that activity. He also works with the Star Legacy Foundation. The Star Legacy Fouundation is a stillbirth advocacy group. Dr. Nicholson has been provided travel and lodging to several meetings organized by this foundation over the past three years. Otherwise, the authors have no conflict of interest to report with regard to this publication.

\section{Authorship criteria -}

1. Gergorio DEL BOCA - Dr. DEL BOCA is currently the "Primario" of the Obstetrics Department at the Mandic Hospital. He was an active member of the 3-person OB group that used AMORIPAT during the 18 month period of clinical activity reported by this manuscript. Dr. DEL BOCA developed the DEL BOCA Method that is described in the manuscript (the Italian version of AMOR-IPAT). He was involved with the conceptualization of the study and was involved with data abstraction, drafting of several original versions of the study and reviewed multiple version of the manuscript. He has provided final approval of the version of the manuscript that is being submitted.

2. Anna Biffi, MD - Dr. Biffi was an active member of the 3-person OB group that used AMOR-IPAT during the 18 month period of clinical activity reported by this manuscript. Dr. Biffi was the individual who connected the Italian team with USA AMOR-IPAT providers. She was involved with the conceptualization of the study and was involved with data abstraction, drafting of several original versions of the study and reviewed multiple version of the manuscript. She has provided final approval of the version of the manuscript that is being submitted.

3. Roberto Zagni, MD - Dr. Zagni was the "Primario" of the Obstetrics Department at the Mandic Hospital during the time period the clinical portion of this study occurred. He was also the senior member of the 3-person group during that time. He was involved with the conceptualization of the study and was involved with data abstraction, drafting of several original versions of the study and reviewed multiple version of the manuscript. He has provided final approval of the version of the manuscript that is being submitted.

4. Antonio Montanari, M.D. - Dr. Montanari is an anesthesiologist who worked at the Mandic Hospital during the time the clinical activity for the Italian study was taking place. He helped with data abstraction and was involved with drafting and editing the study manuscript. He has provided final approval of the version of the manuscript that is being submitted.

5. James Nicholson, M.D., M.S.C.E. - Dr. Nicholson was invited by the primary study group to assist with the development and publication of this study. He assisted with confirmation of data integrity, statistical analysis, and manuscript generation. He has provided final approval of the version of the manuscript that is being submitted.

\section{Acknowledgment}

In the production of this paper, Samantha MacColl-Garfinkel Benjamin assisted with data management, fine-tuning of theoretical constructs, and study communications.

\section{References}

1. Martin JA HB, Ventura SJ, Osterman MJK, Mathews TJ (2013) Births: Final data for 2011. In: reports Nvs, ed. Vol 62. Hyattsville, MD: National Center for Health Statistics:1- 90.

2. Torricelli M, Novembri R, Voltolini C, Conti N, Biliotti G, et al. (2011) Biochemica and biophysical predictors of the response to the induction of labor in nulliparous postterm pregnancy. Am J Obstet Gynecol 204: 39.e31-39.e36. [Crossref]

3. Niino Y (2011) The increasing cesarean rate globally and what we can do about it. Biosci Trends 5: 139-150. [Crossref]

4. Barber EL, Lundsberg LS, Belanger K, Pettker CM, Funai EF, et al. (2011) Indications contributing to the increasing cesarean delivery rate. Obstet Gynecol 118: 29-38. [Crossref]

5. Ecker JL, Frigoletto FD Jr (2007) Cesarean delivery and the risk-benefit calculus. $N$ Engl J Med 356: 885-888. [Crossref]

6. Bailit JL, Love TE, Mercer B (2004) Rising cesarean rates: are patients sicker? Am J Obstet Gynecol 191: 800-803. [Crossref]

7. Declercq E, Menacker F, Macdorman M (2006) Maternal risk profiles and the primary cesarean rate in the United States, 1991-2002. Am J Public Health 96: 867-872. [Crossref]

8. United States. Public Health Service. Healthy people 2000: national health promotion and disease prevention objectives : full report, with commentary. Washington, D.C. U.S. Dept. of Health and Human Services, Public Health Service: For sale by the Supt of Docs., U.S. G.P.O.; 1990.

9. Bruce F, Penny C, Andrea K, Donald B, Jane R (1997) Reducing Cesarean Rates While Maintaining Maternal and Infant Outcomes. Boston, Mass: Institute of Health Care Improvement.

10. Liu S LR, Joseph KS, Heaman M, Sauve R, Kramer MS (2007) Maternal Health Study Group of the Canadian Perinatal Surveillance System. Maternal mortality and severe morbidity associated with low-risk planned cesarean delivery versus planned vaginal delivery at term. CMAJ 176: 455-460. [Crossref] 
11. Fogelson NS, Menard MK, Hulsey T, Ebeling M (2005) Neonatal impact of elective repeat cesarean delivery at term: A comment on patient choice cesarean delivery. Am J Obstet Gynecol 192: 1433-1436. [Crossref]

12. Druzin ML, El-Sayed YY (2006) Cesarean delivery on maternal request: wise use of finite resources? A view from the trenches. Semin Perinatol 30: 305-308. [Crossref]

13. Deneux-Tharaux C, Carmona E, Bouvier-Colle MH, Breart G (2006) Postpartum maternal mortality and cesarean delivery. Obstet Gynecol 108: 541-548. [Crossref]

14. Minkoff H, Chervenak FA (2003) Elective primary cesarean delivery. $N$ Engl $J$ Med 348: 946-950. [Crossref]

15. Conroy K, Koenig AF, Yu YH, Courtney A, Lee HJ, et al. (2012) Infectious morbidity after cesarean delivery: 10 strategies to reduce risk. Rev Obstet Gynecol 5: 69-77. [Crossref]

16. American College of Obstetricians and Gynecologists (2013) ACOG committee opinion no. 559: Cesarean delivery on maternal request. Obstet Gynecol 121: 904-907. [Crossref]

17. Burcher P, Gabriel JL, Campo-Engelstein L, Kiley KC (2013) The case against cesarean delivery on maternal request in labor. Obstet Gynecol 122: 684-687. [Crossref]

18. Dietz HP (2006) Pelvic floor trauma following vaginal delivery. Curr Opin Obstet Gynecol 18: 528-537. [Crossref]

19. Lukacz ES, Lawrence JM, Contreras R, Nager CW, Luber KM (2006) Parity, mode of delivery, and pelvic floor disorders. Obstet Gynecol 107: 1253-1260. [Crossref]

20. Hannah ME, Whyte H, Hannah WJ, Hewson S, Amankwah K, et al. (2004) Maternal outcomes at 2 years after planned cesarean section versus planned vaginal birth for breech presentation at term: the international randomized Term Breech Trial. Am J Obstet Gynecol 191: 917-927. [Crossref]

21. Kennare R, Tucker G, Heard A, Chan A (2007) Risks of adverse outcomes in the next birth after a first cesarean delivery. Obstet Gynecol 109: 270-276. [Crossref]

22. Thompson JF, Roberts CL, Currie M, Ellwood DA (2002) Prevalence and persistence of health problems after childbirth: associations with parity and method of birth. Birth 29: 83-94. [Crossref]

23. Ecker J (2013) Elective cesarean delivery on maternal request. JAMA 309: 1930-1936. [Crossref]

24. Nicholson JM, Yeager DL, Macones G (2007) A preventive approach to obstetric care in a rural hospital: Association between higher rates of preventive labor induction and lower rates of cesarean delivery. Ann Family Med 5: 310-319. [Crossref]

25. Bujold E, Blackwell SC, Hendler I, Berman S, Sorokin Y, Gauthier RJ (2004) Modified Bishop's score and induction of labor in patients with a previous cesarean delivery. $\mathrm{Am}$ J Obstet Gynecol 191: 1644-1648. [Crossref]

26. Hartmann KE, Andrews JC, Jerome RN, Lewis RM, Likis FE, et al. (2012) Strategies to Reduce Cesarean Birth in Low-Risk Women. Rockville (MD).

27. Nicholson JM, Kellar LC, Cronholm PF, Macones GA (2004) The active management of risk in pregnancy at term in an urban population: An association between a higher induction of labor rate and a lower cesarean delivery rate. Am J Obstet Gynecol 91: 1516-1528. [Crossref]

28. Nicholson JM, Cronholm P, Kellar LC, Stenson MH, Macones GA (2009) The association between increased use of labor induction and reduced rate of cesarean delivery. $J$ Womens Health (Larchmt) 18: 1747-1758. [Crossref]

29. Nicholson JM, Stenson MH, Kellar LC, Caughey AB, Macones GA (2009) The active management of risk in nulliparous pregnancy at term: Association between a higher preventive labor induction rate and improved birth outcomes. Am J Obstet Gynecol 200: 254.e251-254.e213. [Crossref]

30. Nicholson JM, Caughey AB, Stenson MH, Cronholm P, Kellar L, et al. (2009) The active management of risk in multiparous pregnancy at term: Association between a higher preventive labor induction rate and improved birth outcomes. Am J Obstet Gynecol 200: 250.e251-250.e213. [Crossref]

31. Nicholson JM, Kellar LC, Kellar GM (2006) The impact of the interaction between increasing gestational age and obstetrical risk on birth outcomes: evidence of a varying optimal time of delivery. J Perinatol 26: 392-402. [Crossref]

32. Nicholson JM, Holt M (2005) Will active management of obstrectric risk lower C/S rates? Contemporary $O B / G Y N$ 50: 38-53.

33. Sanchez-Ramos L, Kaunitz AM, Delke I, Gaudier FL (1999) Cervical ripening and labor induction with a controlled-release dinoprostone vaginal insert: a meta-analysis.
Obstet Gynecol 94: 878-883. [Crossref]

34. Xenakis EM, Piper JM, Conway DL, Langer O (1997) Induction of labor in the nineties: conquering the unfavorable cervix. Obstet Gynecol 90: 235-239. [Crossref]

35. Nielsen PE, Goldman MB, Mann S, et al. (2007) Effects of teamwork training on adverse outcomes and process of care in labor and delivery: a randomized controlled trial. Obstet Gynecol 109: 48-55. [Crossref]

36. Rosenstein MG, Cheng YW, Snowden JM, Nicholson JM, Caughey AB (2012) Risk of Stillbirth and Infant Death Stratified by Gestational Age. Obstet Gynecol 120: 76-82. [Crossref]

37. Ehrenthal DB, Hoffman MK, Jiang XZ, Ostrum G (2011) Neonatal Outcomes After Implementation of Guidelines Limiting Elective Delivery Before 39 Weeks of Gestation. Obstet Gynecol 118: 1047-1055. [Crossref]

38. Nicholson JM, Kellar LC, Ahmad S, Abid A, Woloski J, et al. (2016) US term stillbirth rates and the 39-week rule: a cause for concern? Am J Obstet Gynecol 214: 621. [Crossref]

39. Grimes DA, Schulz KF (2012) False alarms and pseudo-epidemics: the limitations of observational epidemiology. Obstet Gynecol 120: 920-927. [Crossref]

40. Wood S, Cooper S, Ross S (2013) Does induction of labour increase the risk of caesarean section? A systematic review and meta-analysis of trials in women with intact membranes. BJOG 121: 674-685. [Crossref]

41. Stock SJ, Ferguson E, Duffy A, Ford I, Chalmers J, et al. (2012) Outcomes of elective induction of labour compared with expectant management: population based study. BMJ 344: e2838. [Crossref]

42. Darney BG, Snowden JM, Cheng YW, Jacob L, Nicholson JM, et al. (2013) Elective Induction of Labor at Term Compared with Expectant Management: Maternal and Neonatal Outcomes. Obstet Gynecol 122: 761-769. [Crossref]

43. Tillett J (2007) Elective induction of labor: not without risks for mother and infant. $J$ Perinat Neonatal Nurs 21: 2-3. [Crossref]

44. Yeast JD, Jones A, Poskin M (1999) Induction of labor and the relationship to cesarean delivery: A review of 7001 consecutive inductions. Am J Obstet Gynecol 180: 628-633. [Crossref]

45. Maslow AS, Sweeny AL (2000) Elective induction of labor as a risk factor for cesarean delivery among low-risk women at term. Obstet Gynecol 95: 917-922. [Crossref]

46. Jonsson M, Cnattingius S, Wikström AK (2013) Elective induction of labor and the risk of cesarean section in low-risk parous women: a cohort study. Acta Obstet Gynecol Scand 92: 198-203. [Crossref]

47. Cammu H, Martens G, Ruyssinck G, Amy JJ (2002) Outcome after elective labor induction in nulliparous women: a matched cohort study. Am J Obstet Gynecol 186 240-244. [Crossref]

48. Ben-Haroush A, Yogev Y, Bar J, Glickman H, Kaplan B, et al. (2004) Indicated labor induction with vaginal prostaglandin E2 increases the risk of cesarean section even in multiparous women with no previous cesarean section. J Perinat Med 32: 31-36. [Crossref]

49. ACOG Committee on Practice Bulletins -- Obstetrics (2009) ACOG Practice Bulletin No. 107: Induction of labor. Obstet Gynecol 114: 386-397. [Crossref]

50. Mozurkewich EL, Chilimigras JL, Berman DR, Perni UC, Romero VC, et al. (2011) Methods of induction of labour: a systematic review. BMC Pregnancy Childbirth 11: 84. [Crossref]

51. Bailit JL, Ohio Perinatal Quality Collaborative (2010) Rates of labor induction without medical indication are overestimated when derived from birth certificate data. $A m J$ Obstet Gynecol 203: 269 e1-3. [Crossref]

52. Källén B (2012) The problem of confounding in studies of the effect of maternal drug use on pregnancy outcome. Obstet Gynecol Int 2012: 148616. [Crossref]

53. Signorello LB, McLaughlin JK, Lipworth L, Friis S, Sørensen HT, et al. (2002) Confounding by indication in epidemiologic studies of commonly used analgesics. $\mathrm{Am}$ $J$ Ther 9: 199-205. [Crossref]

54. Caughey AB, Nicholson JM, Cheng YW, Lyell DJ, Washington AE (2006) Induction of labor and cesarean delivery by gestational age. Am J Obstet Gynecol 195: 700-705. [Crossref]

55. Caughey AB (2012) Elective induction of labour is associated with decreased perinatal mortality and lower odds of caesarean section at 40 and 41 weeks. Evi Based Med 18 : 117-118. [Crossref]

56. McLachlan HL, Forster DA, Davey MA, Farrell T, Gold L, et al. (2012) Effects of 
Boca GD (2017) The association between the regular use of risk-based term IOL and improved birth outcomes in an Italian hospital: A retrospective cohort study

continuity of care by a primary midwife (caseload midwifery) on caesarean section rates in women of low obstetric risk: the COSMOS randomised controlled trial. BJOG 119: 1483-1492. [Crossref]
57. ACOG Committee on Practice Bulletins -- Obstetrics (2009) ACOG Practice Bulletin No. 107: Induction of labor. Obstet Gynecol 114: 386-397. [Crossref]

Copyright: (C2017 Boca GD. This is an open-access article distributed under the terms of the Creative Commons Attribution License, which permits unrestricted use, distribution, and reproduction in any medium, provided the original author and source are credited. 